\title{
A inclusão de alunos com TDAH \\ - um decênio das diretrizes de Educação Especial em Santa Catarina: um modelo de beneficência?*
}

\author{
Simone Schelbauer Moreira Paes a \\ Valquíria Elita Renk ${ }^{b}$ \\ Daiane Priscila Simão-Silva ${ }^{c}$
}

\section{Resumo}

Nesse artigo, pretendemos discutir a presença do mínimo ético da beneficência nas diretrizes de inclusão dos alunos com transtorno de déficit de atenção/hiperatividade (TDAH), adotada pelo estado de Santa Catarina, pioneiro em diretrizes norteadoras de inclusão. Para tanto, foi realizada uma análise de conteúdo das diretrizes da Educação Especial de Santa Catarina, no período de 2006 a 2016, a partir de um referencial da bioética. No contexto de Educação inclusiva, faz-se necessário superar a visão paternalista, priorizando a promoção da autonomia dos alunos. A partir da análise de um mínimo ético nas relações escolares, identificou-se que as diretrizes contemplam o princípio da beneficência num contexto em que os alunos com TDAH são vistos apenas como um problema de saúde. Contudo, a garantia efetiva da inclusão escolar carece da inserção de princípios como os preconizados na Declaração Universal em Bioética e dos Direitos Humanos.

Palavras-chave: Beneficência. TDAH. Bioética.

\section{Introdução}

A inclusão educacional, como direito universal de igualdade e de respeito pela vida humana, está relacionada ao atendimento da diversidade dos alunos com

\footnotetext{
* O presente artigo tem como base a pesquisa realizada durante o mestrado de Simone Schelbauer Moreira Paes, contemplada com bolsa da Coordenação de Aperfeiçoamento de Pessoal de Nível Superior.

a Pontifícia Universidade Católica do Paraná, Curitiba, PR, Brasil; Escola de Educação Básica Professora Maria Paula Feres, Mafra, Santa Catarina, Brasil.

b Pontifícia Universidade Católica do Paraná, Curitiba, PR, Brasil.

c Instituto para Pesquisa do Câncer, Guarapuava, PR, Brasil.
} 
necessidades educacionais especiais em escolas de Ensino Básico (BRASIL, 2008). Porém, pressupõe-se que o processo de inclusão do público-alvo da Educação Especial é atual e impositivo, aflorando alguns conflitos éticos nas relações escolares, dentre eles, destacam-se a estigmatização, a discriminação, a exclusão e as demais vulnerabilidades. Para firmar a concretização da inclusão no ambiente escolar, precisam ser considerados alguns princípios éticos mínimos, tais como o respeito ao direito à Educação, à dignidade humana, à equidade e à justiça quanto à implementação de políticas inclusivas.

É direito humano básico a não discriminação e a não estigmatização, em respeito às liberdades fundamentais. $\mathrm{O}$ estigma se caracteriza quando o outro é inferiorizado e diminuído dos demais seres humanos, com rótulos, por exemplo, levando-o à perda de status e à discriminação, que desqualifica, rejeita e exclui a pessoa vitimizada, comprometendo a sua qualidade de vida (GODOI; GARRAFA, 2014).

O público-alvo da Educação Especial inclusiva contemplado no estado de Santa Catarina é amplo, geralmente, com sinais clínicos e físicos característicos, como ocorre na deficiência intelectual, visual, auditiva ou física, ou ainda, em transtornos como o do espectro autista e o de altas habilidades/superdotação. Ademais, são inseridos também os alunos com transtorno de déficit de atenção/hiperatividade (TDAH), cujo reconhecimento e diferenciação dos sinais clínicos, de modo geral, não são tão axiomáticos, dificultando o processo de inclusão.

O TDAH é um transtorno de etiologia multifatorial, "considerando a conjugação de fatores genéticos, ambiente familiar e história gestacional" (NARDI et al., 2015, p. 28). Afetando globalmente cerca de $7,2 \%$ das crianças, o TDAH é caracterizado pelo desenvolvimento em níveis inadequados de desatenção, de impulsividade e de hiperatividade (CHADD, 207; THOMAS et al., 2015). A identificação do TDAH ocorre principalmente em idade escolar, com o comprometimento na realização das atividades e pela inquietação em sala de aula (APA, 2017).

O cenário da Educação Inclusiva no Brasil teve sua tendência histórica preconizado e oficializado na Constituição Federal de 1988, por meio do artigo 205, descrevendo que a promoção da Educação deve ser realizada "com igualdade de condições de acesso e de permanência na escola" (BRASIL, 1988, p. 136). A Lei de Diretrizes e Bases da Educação Nacional (BRASIL, 1996) também mencionava diretrizes sobre a inclusão (artigos 58, 59 e 60) e a nova redação dessa lei (BRASIL, 2013) altera a especificação desse público-alvo para os alunos que possuem deficiências, transtornos globais de desenvolvimento e de altas habilidades/superdotação, não incluindo os diagnosticados com TDAH. Tal alteração equipara-se com outra 
Diretriz Nacional que norteia a Educação Especial no Brasil, destacada atualmente e denominada de Política Nacional de Educação Especial na Perspectiva da Educação Inclusiva (PNEEPEI), vigorando desde o ano de 2008. Em ambas as diretrizes, o TDAH não é contemplado de forma específica.

Nesse contexto histórico, a presente análise ocorreu no estado de Santa Catarina, que implementou suas Diretrizes de Educação Especial em 2006, antecedendo os demais estados brasileiros, diferenciando-se em âmbito temporal nacional e no aspecto de público-alvo inclusivo, considerando também os alunos com TDAH. O estado apresenta um programa de inclusão visando oferecer apoio e acolhimento para esses alunos, por meio do serviço do segundo professor de turma e do serviço de atendimento educacional especializado (Saede) (FCEE, 2009).

Simultaneamente ao professor titular, o segundo professor de turma deve acompanhar, de forma permanente, todo o desenvolvimento escolar do estudante considerado incluso, dentre outras atribuições que estão discriminadas no teor do Programa Pedagógico de Santa Catarina (FCEE, 2009). O serviço de atendimento educacional especializado dispõe de um professor de Educação Especial por escola, sendo que esse profissional terá de assessorar e apoiar o segundo professor de turma e os demais professores da sala de aula que trabalham com o público-alvo da Educação Especial, envolvendo os alunos com TDAH, propondo intervenções como estratégias/metodologias adequadas para atuarem no ensino inclusivo (FCEE, 2009).

Segundo a mais recente Diretriz de Educação Especial de Santa Catarina, a Resolução n ${ }^{\circ}$ 100/2016, do Conselho Estadual de Educação (CEE), houve alteração na disponibilidade do segundo professor de turma aos alunos que possuem somente TDAH, sendo esses, inicialmente, desprovidos desse serviço (SANTA CATARINA, 2016), gerando diversas discussões e conflitos entre alunos com o transtorno, os pais, os professores, a gestão escolar e a gerência estadual. No mesmo documento, considera-se que os alunos com TDAH serão contemplados com o serviço do segundo professor de turma apenas quando apresentarem comorbidades com diagnóstico de deficiência intelectual, transtorno do espectro autista, deficiência múltipla ou física (SANTA CATARINA, 2016). Conforme o que consta no caderno da Política de Educação Especial da Secretaria de Educação de Santa Catarina, um dos motivos que levou a essa mudança na diretriz deve-se à adequação à Política Nacional de Educação Especial na Perspectiva da Educação Inclusiva, do Ministério da Educação (SED-SC, 2018). Porém, não foram encontradas informações documentais mais precisas sobre tal alteração do segundo professor de turma. 
É nesse contexto que se optou em discutir a Educação Inclusiva dos alunos com TDAH, a partir do princípio da beneficência. Esse emerge como princípio da corrente da bioética principialista, enunciada por Beauchamp e Childress, em 1979, e é caracterizada pela justificação moral. Ela está pautada na teoria da moralidade comum, que constitui uma convergência moral global, com normas que devem ser apropriadas a cada ser humano (VEATCH, 1999), baseada na história da pessoa, não como um padrão mundial ou que poderá ser garantida por todos de forma lógica e racional (GORDON et al., 2011). Além da beneficência, tal teoria é constituída por mais três princípios, denominados como autonomia, não maleficência e justiça, os quais são propostas éticas gerais para a área da saúde, sendo que um princípio não tem prioridade sobre o outro e não são absolutos (BEAUCHAMP; CHILDRESS, 2013).

Nesse cenário, compreende-se que o princípio da beneficência não abrange a totalidade da Educação Inclusiva, mas pode ser utilizado como base inicial e fundamental para averiguar os requisitos normativos mínimos na promoção da inclusão no contexto escolar. Além disso, o estudo se constitui de uma reflexão propositiva de atuação dos profissionais da Educação que promova o processo de inclusão de forma a considerar as competências e as habilidades desses alunos.

Para a finalidade da promoção da inclusão, foi analisado se o princípio da beneficência, da bioética principialista, está sendo contemplado nas Diretrizes da Política de Educação Especial do Estado de Santa Catarina/2006, da Resolução $\mathrm{n}^{\mathrm{o}}$ 112/2006 CEE/SC, que fixa normas para a Educação Especial/SC, do Programa Pedagógico de Educação Especial/2009/SC e da Resolução no 100/2016 CEE/SC (SANTA CATARINA, 2016), que estabelecem novas Diretrizes para a Educação Especial/SC, no que se refere à inclusão dos alunos com TDAH.

\section{Método}

A pesquisa foi realizada utilizando o método analítico qualitativo, por meio da análise documental referente às Diretrizes da Educação Especial de Santa Catarina, no período de 2006 a 2016. Tal análise foi conduzida por meio do método de práticas discursivas formulada por Spink e Medrado (2013), por elementos lexicais, na forma conjunta pelos pares, e consistiu em uma adaptação nas etapas dos estudos de Oliveira (2010).

O primeiro passo da análise documental foi um recorte dos documentos que norteiam a Educação Especial no estado de Santa Catarina. Após a leitura introdutória das diretrizes, procurou-se demarcar as categorias de análise, a partir de elementos lexicais como palavras ou sentidos, relacionando-os ao princípio 
da beneficência, que lhes são associadas. Com o propósito de atingir o objetivo e verificar se estavam de acordo com os conceitos de Beauchamp e Childress (2013), retomou-se a leitura dos documentos levantados para identificar as categorias assinaladas no texto.

Depois da análise dos sentidos extraídos de cada repertório, foi feita a busca de elementos em comum, no que se refere ao princípio da beneficência, entre os variados sentidos extraídos dos repertórios e a identificação de sentidos compartilhados. Posteriormente, construiu-se um mapa conceitual de associação de ideias no programa CmapTools, contendo a colagem dos repertórios e a análise dos sentidos compartilhados encontrados, conforme especificado no Quadro 1 (Anexo 1).

Por fim, efetuou-se a conclusão da análise dos sentidos compartilhados para o princípio da beneficência, correspondentes à Educação Inclusiva dos alunos com TDAH, nos documentos avaliados.

\section{A Beneficência nas Diretrizes de Educação Especial de Santa Catarina}

No presente estudo de caso, realizado com documentos que compreendem um decênio de significativas mudanças no que tange a um mínimo ético para inclusão dos alunos com TDAH, em um estado que é referência no tema da inclusão, verificou-se que o princípio da beneficência está presente nos quatro documentos avaliados, sendo abordado, predominantemente, no sentido paternalista. Para Beauchamp e Childress (2013, p. 298) "o paternalismo sempre envolve alguma forma de interferência ou de recusa em aceitar as preferências de uma outra pessoa acerca do seu próprio bem", num ato de beneficência análogo à parental. A justificação do paternalismo "considera que o benefício está numa escala com interesses de autonomia, na qual ambos devem ser ponderados" (BEAUCHAMP; CHILDRESS, 2013, p. 306), ou seja, a prevenção de danos, propiciando benefícios importantes, mesmo que desrespeite um pouco a autonomia (BEAUCHAMP; CHILDRESS, 2013). Porém, na área da Educação Inclusiva, o Estado assume o papel paternalista na compreensão de que a inclusão se dá num contexto de autonomia reduzida por parte dos alunos incluídos (como os portadores de TDAH), e, dessa forma, se replicado nas unidades escolares, pode comprometer o processo inclusivo.

A respeito do "Paternalismo de Estado", Schramm (2014) ressalta o que foi citado no Manifesto em Defesa da Civilização, no qual "o bem-estar de um só é possível 
quando os demais à sua volta se encontram na mesma situação e a liberdade só é possível com igualdade e respeito ao outro, pois a autonomia do indivíduo significa a liberdade de se autorrealizar" (SCHRAMM, 2014, p. 12), designado como "ética da solidariedade". Com isso, presume-se que compete ao Estado, além da sociedade, expressar amplitude global nos elementos que caracterizam os alunos com TDAH, como o biológico, o afetivo, o sociocultural e o espiritual, pois eles necessitam de uma proteção mais abrangente no processo de ensino e de aprendizagem, levando em consideração uma Educação pautada em Direitos Humanos e no seu empoderamento visando à promoção da autonomia.

A beneficência premente nas normativas consiste na inserção do aluno com TDAH na Educação Inclusiva, reconhecendo a importância de ele receber um tratamento diferenciado dos demais. $\mathrm{O}$ fator de destaque lexical da beneficência, encontrado nos documentos, foi o suporte educativo a partir de serviços especiais oferecidos pelo Estado como benefício para o processo interdisciplinar da Educação Especial. Destacam-se o "Serviço de atendimento educacional especializado (Saede) [...] e o professor de Educação Especial nas turmas que tiverem estudantes com diagnóstico de condutas típicas" (FCEE, 2006, p. 25), caracterizado como TDAH, ambos com caráter de apoio, complemento ou suplemento na aprendizagem. A saber, por meio das leituras nas diretrizes, observaram-se alterações na nomenclatura desses dois serviços. Na diretriz do Programa Pedagógico, de 2009, ocorreu a mudança de professor de Educação Especial, que passou a denominar-se de segundo professor de turma. Quanto ao Saede, a Resolução $n^{\circ}$ 100/2016 modificou a nomenclatura para Atendimento Educacional Especializado (AEE), objetivando aproximações da Educação Especial em nível nacional (SANTA CATARINA, 2016).

Outro trecho condizente com a beneficência aos alunos incluídos detalha sobre o modo de atuação do serviço do segundo professor de turma. Somado à laboração do professor titular, na rede regular de Educação, sua função é de ser "corregente nas turmas de séries iniciais do Ensino Fundamental e colaborador do professor nas séries finais do Ensino Fundamental e do Ensino Médio" (FCEE, 2009, p. 6), bem como de apoio, nesse último. Salientando propósitos diferenciados, observou-se nestas funções que a palavra "corregente" deriva de reger a turma com o professor titular, contribuir com "a proposição de procedimentos diferenciados [...] e acompanhar o processo de aprendizagem de todos os estudantes" (p. 16). Para a função de colaborar ou apoiar o professor regente, restringe-se apenas "no desenvolvimento das atividades pedagógicas" (p. 16), nas séries finais do Ensino Fundamental, deixando de ser abordado para o Ensino Médio. Esse ato demonstra a exclusão dos alunos incluídos do Ensino Médio de um processo equitativo de aprendizagem e, consequentemente, da sua permanência na escola. 
Dessa maneira, verificou-se que ambas as definições, segundo o professor ou o corregente, tendem a gerar ambiguidades e que são propensas a prejudicar esse serviço de qualificação nas práxis pedagógicas, em que estão inseridos, intrinsecamente, os alunos com TDAH. Para tanto, seria prudente e beneficente "eliminar as condições que causarão danos a outros" (BEAUCHAMP; CHILDRESS, 2013, p. 284), equiparando o teor das funções para todos os níveis de ensino.

\section{A Beneficência no Reconhecimento do TDAH}

Um dos elementos léxicos da beneficência foi identificado no ato de integrar a Educação Especial no Sistema Estadual de Educação Regular de Santa de Catarina, descrito na Resolução $n^{0}$ 112/2006. Mesmo agindo de modo paternalista, pressupõe-se que o Estado realizou uma "ação em benefício dos outros" (BEAUCHAMP; CHILDRESS, 2013, p. 282), a qual inclui os alunos com TDAH de "comportamento hiperativo" e de "desatenção marcante" (SANTA CATARINA, 2006), compreendendo que se considerou a promoção do bem-estar desses, no ensino regular.

Pôde ser destacada no documento de Política de Educação Especial de Santa Catarina, a beneficência aos alunos com TDAH a partir do desenvolvimento de mecanismos de compreensão e de desenvolvimento das potencialidades e das singularidades dos diferentes, como sujeito de direitos, e quando o Estado dispõe de recursos e de serviços especiais para que isso aconteça, tornando possível a permanência desses em escolas de qualidade (FCEE, 2006). Esse entendimento é corroborado pelo Plano Nacional de Educação em Direitos Humanos, com a afirmação de que "a Educação ganha, portanto, mais importância quando direcionada ao pleno desenvolvimento humano e às suas potencialidades, valorizando o respeito aos grupos socialmente excluídos" (BRASIL, 2007, p. 25).

Outra propiciação da beneficência foi observada na Resolução $\mathrm{n}^{\circ} 112$ (SANTA CATARINA, 2006) e no documento da Política de Educação Especial de Santa Catarina, que se referem às adaptações curriculares, na adequação das avaliações e no planejamento diferenciado das atividades escolares. Distinguiu-se o fragmento em que "as escolas devem responder às necessidades educacionais especiais de seus alunos, considerando a complexidade e a heterogeneidade dos estudantes e, consequentemente, dos ritmos de aprendizagem" (FCEE, 2009, p. 11). O Estado, ao normatizar o atendimento dos alunos em suas especificidades, desenvolve um bem, mas também exige que se cumpra com a responsabilidade de propiciar as vias necessárias para tal acolhida. Esses benefícios devem considerar a diversidade dos alunos incluídos, como uma garantia do Sistema Estadual de 
Educação (FCEE, 2006; SANTA CATARINA, 2006), que poderão assegurar uma Educação equitativa aos alunos com o transtorno em estudo. Contudo, pressupõe-se que, ao trabalhar com os alunos as adaptações curriculares de diversas maneiras, o professor praticará a beneficência e a justiça, outrossim, encontrar-se-á realizando atos de solidariedade e de cooperação, como atributos éticos importantes na sua profissão. Isso pode ocorrer também com toda a turma, por meio de estratégias diversificadas, como, por exemplo, de socialização nas atividades em grupos, refletindo em vínculos relacionais com os colegas, na forma de maior aceitação do aluno com TDAH, além de desenvolver a sua identidade e a sua autonomia.

No contexto de inclusão dos alunos com TDAH, Wienen et al. (2019) e Boon (2020) afirmam que o cenário que precede o processo de inserção é o reconhecimento do transtorno pelos professores, sendo esse um assunto ainda desconhecido por eles, devido à grande quantidade de classificações distintas para essa condição. Com essa ausência do reconhecimento, os alunos vulnerados pelo TDAH são estigmatizados como hiperativos, bagunceiros, irresponsáveis, preguiçosos e distraídos. Desconsidera-se o potencial de aprendizado desses alunos, que necessita ser explorado por meio de uma Educação Inclusiva que leve em consideração suas diferenças, respeitando seus estilos e seus ritmos de aprendizagem na sua integralidade, proporcionando melhoria em sua qualidade de vida (PAES; SIMÃO-SILVA, 2015).

Nessa perspectiva, uma parte desse conhecimento refere-se à compreensão do diagnóstico do TDAH, sendo que ela está regulamentada na Lei $\mathrm{n}^{\circ} 15.113$, de 19 de janeiro de 2010, no estado de Santa Catarina, que autoriza a implantação do programa de identificação e de tratamento do transtorno do déficit de atenção e hiperatividade na rede estadual de ensino, com ênfase para o Ensino Fundamental. Dessa maneira, ela se complementa prevendo a capacitação permanente dos professores e, além disso, sua execução deverá ser viabilizada pela integração das Secretarias de Estado da Saúde e da Educação (SANTA CATARINA, 2010). No entanto, há necessidade de sair dessa visão médica apenas e ampliar para a visão social, nas relações humanas, potencializando os alunos com TDAH a desenvolverem o princípio da autonomia, tendo em vista agirem de acordo com suas próprias decisões éticas e morais para conviverem em sociedade, e que, para isso, o professor é o caminho fundamental.

Por conseguinte, no processo de formação continuada para professores, propõe-se uma reflexão crítica sobre "Educação em bioética", por meio da promoção de outros princípios, como da não discriminação, da não estigmatização, da igualdade, da 
justiça, da solidariedade, da cooperação, dentre outros descritos na Declaração Universal em Bioética e Direitos Humanos (DUBDH) (UNESCO, 2005). Por meio dessa ponte entre Educação e bioética, pode-se debater sobre adequações dos valores éticos presentes nesse contexto, sobre o respeito pelos Direitos Humanos e pelas liberdades fundamentais, entre outros (FACURY; SOUZA, 2016).

Mediante a magnitude de toda essa conjuntura, pressupõe-se que uma das debilidades iniciais que precisa ser superada é o reconhecimento do TDAH pelos profissionais da Educação, em geral, para obter a promoção da autonomia e dos Direitos Humanos básicos. Sendo assim, entende-se que a superação do desafio de realizar uma Educação Inclusiva passa pela acolhida e pelo respeito efetivo aos alunos, gerando novos comportamentos e transformação plena do indivíduo que poderão refletir numa sociedade mais justa e mais equitativa.

\section{A Beneficência no Processo de Inclusão}

Ao mencionar sobre a qualificação profissional, vista aqui como benefício aos alunos com TDAH, compreendeu-se que a Fundação Catarinense de Educação Especial (FCEE), instituição parceira da Secretaria da Educação do Estado (SED), estabelece convênios com outras organizações governamentais e não governamentais "mediante cedência e capacitação de profissionais" (FCEE, 2006, p. 40). Essa ação faz-se necessária para superar uma parte considerável dos desafios de uma Educação Inclusiva, tendo em vista "tomar atitudes positivas para ajudar os outros [...] incluindo a prevenção de danos e a eliminação de condições prejudiciais" (BEAUCHAMP; CHILDRESS, 2013, p. 281). Consequentemente, supõe-se que quando esse profissional receber uma capacitação específica, para atuar junto aos seus alunos com TDAH, poderá evitar o dano de não proporcionar o ensino e a aprendizagem de forma adequada.

Outro elemento léxico da beneficência identificado nos documentos, descreve que "o processo de inclusão [...] deve ser compreendido como compromisso de toda sociedade" (FCEE, 2006, p. 40). Para tanto, esse processo deve se concretizar por meio do compartilhamento de responsabilidades, com o envolvimento de diversos segmentos. Como por exemplo das famílias, mediante intervenções junto ao aluno incluído, orientadas pelo setor escolar e da saúde; da parceria com a FCEE, na forma de ceder e de capacitar os professores para atuarem nesse contexto inclusivo; da Secretaria de Saúde, sendo que essa "prestará atendimento especializado (médico e psicológico) a esse estudante" (FCEE, 2006, p.35), referindo-se especialmente ao que possui TDAH. Nesse quesito da saúde, presume-se que o Estado tem tanto a obrigação de "promover o bem-estar do paciente" (BEAUCHAMP; CHILDRESS, 2013 , p. 292) quanto o dever de prover esse direito a todos os cidadãos. Com 
isso, cuidar da saúde dos alunos com TDAH pode resultar em potencializar o aprendizado e em contribuir com uma vida autônoma na sociedade.

À saúde, acrescentam-se "as áreas do Bem-Estar Social, Trabalho e Renda e da Infraestrutura" (SANTA CATARINA, 2006, p. 7). Para que isso transcorra, inclui-se a informação de que o Poder Público "promoverá a articulação com as demais Secretarias de Estado, órgãos municipais, federais e empresas ou organismos nacionais e internacionais" (SANTA CATARINA, 2006, p. 7). Nesse recorte lexical, tornou-se evidente o paternalismo como "o princípio e a prática da administração paterna” (BEAUCHAMP; CHILDRESS, 2013, p. 297), atuando de modo beneficente, mesmo que não desejável, por meio de medidas protetivas no cuidado integral aos que possuem autonomia reduzida, como os alunos com TDAH.

Da mesma forma, o princípio da beneficência pôde ser percebido nos objetivos da SED e da FCEE. Tais instituições encontram-se imbricadas em formular e em desenvolver, respectivamente, as políticas educacionais para promover a inclusão social, capacitar os professores, "garantir o acesso e a permanência dos alunos na Educação Básica de qualidade" (FCEE, 2009, p. 14), dentre muitas outras ações.

\section{A Beneficência para Promoção da Autonomia}

No ambiente educativo, o papel beneficente dos profissionais da Educação é auxiliar na "passagem ou caminhada da heteronomia para a autonomia" (FREIRE, 2017 , p. 68-69) de todos os alunos, visando promover a sua formação e a sua emancipação para atuarem na sociedade. Nessa perspectiva, Paulo Freire (2017) se refere à importância dos docentes no processo de construção da autonomia do aluno, e entende que ela é complexa e processual. Essa fala de Paulo Freire dialoga com a DUBDH (UNESCO, 2005), especialmente no artigo 3, que referencia que a dignidade e os Direitos Humanos devem ser respeitados em sua totalidade, e no artigo 5, que a autonomia individual merece respeito e uma atenção especial àqueles que não são capazes de exercê-la. Assim, qualquer processo educativo formal deve ser realizado com respeito à dignidade de todos os alunos.

A Educação para a autonomia exige comprometimento, responsabilidade, humildade e tolerância. Paulo Freire (2017) indica que deve haver respeito ao educando, que devem ser considerados os tempos diferenciados de aprendizagem e os limites de cada um, apesar de não especificar aqueles com TDAH. Nesse sentido, o "respeito à autonomia do educando" (FREIRE, 2017, p. 58) e à sua dignidade, são imperativos éticos, pois "sujeitos dialógicos aprendem e crescem na diferença" (p. 59), pois qualquer forma de discriminação é imoral e deve ser combatida. 
Os professores precisam compreender as necessidades e as limitações dos alunos com TDAH e, além disso, Ewe (2019) sugere que isso deve ocorrer elevando vínculos, atuando como base segura e acessível, na forma de proporcionar condições para que cada um deles desenvolva as suas eficiências e sua autonomia para atuarem nos seus projetos de vida. Para tanto, se faz necessária a superação da "pedagogia da negação" (GOMES et al., 2010), para que o aluno com TDAH seja capaz de desenvolver o seu potencial e as suas possíveis eficiências cognitivas de modo significativo no ambiente educacional, tendo em vista ser um agente autônomo nas relações sociais. Além disso, deve se considerar a promoção da autonomia e a dignidade de cada um como uma obrigação ética. Contudo, a autonomia é limitada para todos os alunos, sendo eles considerados heterônomos. Tal heteronomia é vista como potencial para se promover a autonomia e, no caso dos alunos com TDAH, não se reconhece esse potencial.

Uma pessoa com autonomia reduzida, como do TDAH, "é controlada por outros ou incapaz de deliberar ou agir com base em seus desejos e planos" (BEAUCHAMP; CHILDRESS, 2013, p.138). Nesse sentido, vale destacar que o diagnóstico do TDAH é "baseado na noção de déficit, incapacidade e disfunções atencional, motora e do controle da impulsividade, articulando-os algumas vezes a problemas comportamentais no âmbito familiar" (LACET; ROSA, 2017, p. 235). Um modelo proposto por Barkley e Benton (2016), focado nas funções executivas cerebrais, denominado de autorregulação ou de autocontrole, tende a explicitar os déficits cognitivos e comportamentais relacionados ao TDAH. A saber, "o autocontrole tem tudo a ver com ética, ou com a capacidade de agir de acordo com os princípios e com os valores mais elevados que operam em uma sociedade" (SANTOS; FREITAS, 2016, p. 1083). Dessa maneira, o comprometimento nas funções executivas do cérebro de uma pessoa, como por exemplo no controle inibitório, pode influir na tomada de decisão (SIMONETTI, 2015), principalmente quando ela tem dificuldades em inibir o próprio comportamento, fazendo com que tenha uma redução na sua autonomia. Com essa habilidade comprometida, dentre outras, as pessoas mais próximas do seu convívio social são as que poderão manifestar a dosagem ideal no controle do seu comportamento inadequado e, algumas vezes, antissocial.

Entretanto, mesmo que a autonomia na infância seja reduzida, para ser beneficente, a Educação deve ser promotora dessa emancipação, de forma que os alunos com TDAH possam ser "potencializados" nas suas competências e nas suas habilidades, respeitando o seu tempo e almejando seu desenvolvimento e sua aprendizagem. O processo de desenvolvimento de autonomia dos alunos não passa apenas pelas normativas, mas pode se concretizar a partir dos professores, que precisam estar aptos para o processo de Educação Inclusiva. Barkley (2020) cita que a falta de 
formação dos professores é um "problema crítico", sendo necessário reverter essa situação, de modo a realizar avanços para ajudar os alunos com o transtorno a alcançarem o sucesso escolar.

\section{Considerações finais}

O princípio da beneficência foi escolhido para nortear esse artigo pela motivação em buscar um mínimo ético necessário para promoção da inclusão dos alunos com TDAH nas Diretrizes de Educação Especial do Estado de Santa Catarina, uma vez que essas evidenciam o tema sob uma ótica da perspectiva clínica do transtorno. Compreendeu-se, a partir da beneficência, que esse princípio abrange a discussão dos conflitos existentes nas relações humanas, os quais também podem ser abordados no processo inclusivo, em âmbito educacional, dentro das suas limitações.

Dessa forma, a análise das normativas elencam a necessidade de um olhar crítico daqueles que colocarão em prática as Diretrizes da Educação Inclusiva para superação da visão paternalista do Estado. Nesse sentido, a Educação escolar é o caminho para desenvolver as potencialidades e as possíveis eficiências cognitivas dos alunos com TDAH, no intuito de formar um cidadão pleno para atuar com seus projetos de vida na sociedade. Assim, a beneficência é demonstrada a partir de diretrizes que visam ao desenvolvimento de mecanismos de compreensão das potencialidades e das singularidades dos diferentes, como sujeito de direitos. E o Estado dispõe de recursos e de serviços especiais para que isso aconteça, como o segundo professor de turma e o atendimento educacional especializado, tornando possível a permanência desses em escolas de qualidade.

No entanto, presume-se que os professores têm a obrigação de atuar no ambiente formativo de maneira que as consequências da sua prática pedagógica não lesem ou não prejudiquem o comportamento e o aprendizado dos alunos com TDAH, sendo que eles já possuem o comprometimento na sua conduta e nas suas habilidades cognitivas. Além disso, ao acolher e ao ensinar o aluno com TDAH na turma em que está incluído, aceitando e compreendendo o transtorno em foco, acreditando na sua capacidade, o profissional da Educação tornar-se-á intencionalmente assertivo ao princípio da beneficência, promovendo uma qualidade de vida mais digna, já que esse aluno se encontra vulnerado. Contudo, ao reconhecer a heterogeneidade de alunos, como os que possuem TDAH, e ao considerar as suas diferenças, os profissionais da Educação estarão colocando em prática o artigo $11^{\circ}$ da DUBDH, da não discriminação e não estigmatização (UNESCO, 2005), além de "não causar o mal ou dano ao outro" (BEAUCHAMP; CHILDRESS, 2013, p. 209), tendo em vista não violar a dignidade e os Direitos Humanos. 
A partir da análise de um mínimo ético nas relações escolares, identificou-se que as Diretrizes de Educação Especial de Santa Catarina contemplam o princípio da beneficência, num contexto em que os alunos com TDAH são vistos, predominantemente, como um problema de saúde. Porém, isso não é o suficiente e é preciso superar somente esse mínimo. Dessa forma, a presente pesquisa aponta, primordialmente, para a necessidade de que a Educação Inclusiva se efetive de modo mais integral e mais humanitário, levando em consideração também outros princípios, como os de não discriminação, de não estigmatização, de igualdade, de justiça, de solidariedade, de cooperação, dentre outros, descritos na DUBDH, com vistas à garantia do processo de inclusão de forma equitária e promotora dos Direitos Humanos. Estudos futuros podem contribuir de forma prática para a construção de modelos efetivos de beneficência na Educação especial. 


\title{
The inclusion of students with ADHD - a decade of Special education guidelines in Santa Catarina: a model of beneficence?
}

\begin{abstract}
In this article we intend to discuss the presence of the ethical minimum of beneficence in the inclusion policy guidelines of students with attention deficit hyperactivity disorder (ADHD), adopted by the state of Santa Catarina, a pioneer in guidelines for inclusion. For that, a content analysis of the Santa Catarina special education guidelines (2006 to 2016) was carried out, based on a bioethics reference. In the context of inclusive education, it is necessary to overcome the paternalistic view, prioritizing the promotion of student autonomy. From the analysis of an ethical minimum in school relations, it was identified that the guidelines contemplate the principle of beneficence in a context in which students with ADHD are only seen as a health problem; however, the effective guarantee of school inclusion requires the insertions of principles such as those advocated by the Universal Declaration on Bioethics and Human Rights.
\end{abstract}

Keywords: Beneficence. ADHD. Bioethics.

\section{La inclusión de estudiantes con TDAH: uma década de directrices de de Educación Especial en Santa Catarina: ¿Un modelo de beneficiencia?}

\section{Resumen}

En este artículo pretendemos discutir la presencia del beneficio ético mínimo en las pautas de inclusión para estudiantes con trastorno por déficit de atención/hiperactividad (TDAH), adoptadas por el estado de Santa Catarina, pionero en guiar pautas de inclusión. Para ello, se llevó a cabo un análisis de contenido de los lineamientos de Educación Especial en Santa Catarina de 2006 a 2016, con base en un marco de bioética. En el contexto de la educación inclusiva, es necesario superar la visión paternalista, priorizando la promoción de la autonomía de los estudiantes. A partir del análisis de un mínimo ético en las relaciones escolares, se identificó que los lineamientos contemplan el principio de beneficencia en un contexto en el que los estudiantes con TDAH son vistos solo como un problema de salud. Sin embargo, la garantía efectiva de la inclusión escolar requiere la inclusión de principios como los preconizados en la Declaración Universal de Bioética y Derechos Humanos.

Palabras clave: Beneficencia. TDAH. Bioética. 


\section{Referências}

AMERICAN PSYCHIATRIC ASSOCIATION - APA. What Is ADHD?

Washington, DC, 2017. Disponível em: https://www.psychiatry.org/

patients-families/adhd/what-is-adhd. Acesso em: 19 jun. 2020.

BARKLEY, R. A. TDAH: transtorno do déficit de atenção com hiperatividade. Belo Horizonte: Autêntica, 2020.

BARKLEY, R. A.; BENTON, C. M. Vencendo o transtorno de déficit de atenção/hiperatividade: adulto. Porto Alegre: Penso, 2016.

BEAUCHAMP, T.; CHILDRESS, J. Princípios de ética biomédica. 7. ed. São Paulo: Loyola, 2013.

BOON, H. J. What do ADHD neuroimaging studies reveal for teachers, teacher educators and inclusive education? Child \& Youth Care Forum, Cham, v. 49, p. 533-561, jan. 2020. https://doi.org/10.1007/s10566-019-09542-4

BRASIL. Lei n ${ }^{\circ}$ 9.394, de 20 de dezembro de 1996. Estabelece as diretrizes e bases da educação nacional. Diário Oficial da União, Brasília, DF, 23 dez. 1996.

BRASIL. Lei ${ }^{\circ} 12.796$, de 4 de abril de 2013. Altera a lei $n^{\circ} 9.394$, de 20 de dezembro de 1996, que estabelece as diretrizes e bases da educação nacional. Diário Oficial da União, Brasília, DF, 5 abr. 2013.

BRASIL. Ministério da Educação. Plano nacional de educação em direitos humanos. Brasília, DF, 2007.

BRASIL. Ministério da Educação. Política nacional de educação especial na perspectiva da educação inclusiva. Brasília, DF, 2008.

BRASIL. Senado Federal. Constituição da República Federativa do Brasil. Brasília, DF, 1988.

\section{CHILDREN AND ADULTS WITH ATTENTION-DEFICIT/}

HYPERACTIVITY DISORDER - CHADD. About ADHD. Lanham, 2017.

Disponível em: help4adhd.org. Acesso em: 20 jun. 2020.

EWE, L. P. ADHD symptoms and the teacher-student relationship:

a systematic literature review. Emotional and Behavioural

Difficulties, Ashford, v. 24, n. 2, p. 136-155, abr. 2019.

https://doi.org/10.1080/13632752.2019.1597562 
FACURY, I. C. T.; SOUZA, W. Educação: uma ponte para a bioética. In: RENK, V. E. Bioética e educação: múltiplos olhares. Curitiba: Prismas, 2016. p. 87-105.

FREIRE, P. Pedagogia da autonomia: saberes necessários à prática educativa. 55. ed. São Paulo: Paz e Terra, 2017.

FUNDAÇÃO CATARINENSE DE EDUCAÇÃO ESPECIAL - FCEE. Página de busca: programa pedagógico. São José, 2009. Disponível em: goo. gl/FxqJt7. Acesso em: 26 ago. 2020.

FUNDAÇÃO CATARINENSE DE EDUCAÇÃO ESPECIAL - FCEE. Política de educação especial do estado de Santa Catarina. São José, 2006. Disponível em: goo.gl/ZwEzsN. Acesso em: 6 jul. 2020.

GODOI, A. M. M.; GARRAFA, V. Leitura bioética do princípio de não discriminação e não estigmatização. Saúde e Sociedade, São Paulo, v. 23, n. 1, p. 157-166, jan./mar. 2014. https://doi.org/10.1590/S0104-12902014000100012

GOMES, A. L. L. V.; POULIN, J. R.; FIGUEIREDO, R. V. A educação especial na perspectiva da inclusão escolar: o atendimento educacional especializado para alunos com deficiência intelectual. Brasília, DF: Ministério da Educação, 2010.

GORDON, J. S.; RAUPRICH, O.; VOLLMANN, J. Applying the four-principle approach. Bioethics, Quezon City, v. 25, n. 6, p. 293-300, jul. 2011. https://doi.org/10.1111/j.1467-8519.2009.01757.x

LACET, C.; ROSA, M. D. Diagnóstico de transtorno de déficit de atenção e hiperatividade (TDAH) e sua história no discurso social: desdobramentos subjetivos e éticos. Psicologia Revista, São Paulo, v. 26, n. 2, p. 231-253, 2017. https://doi.org/10.23925/2594-3871.2017v26i2p.231-253

NARDI, A. E.; QUEVEDO, J.; SILVA, A. G. Transtorno de déficit de atenção/ hiperatividade: teoria e clínica. Porto Alegre: Artmed, 2015.

OLIVEIRA, A. A. S. Interface entre bioética e direitos humanos: perspectiva teórica, institucional e normativa. Tese (Doutorado em Ciências da Saúde) Faculdade de Ciências da Saúde, Universidade de Brasília, Brasília, DF, 2010. Disponível em: goo.gl/aBP7vb. Acesso em: 9 ago. 2020.

PAES, S. S. M.; SIMÃO-SILVA, D. P. Bioética e educação: a desigualdade de ensino aos alunos portadores de TDAH. In: CONGRESSO BRASILEIRO DE BIOÉTICA, 11., 2015, Curitiba. Anais[...] Brasília, DF: Sociedade Brasileira de Bioética, 2015. Disponível em: goo.gl/9FGRqv. Acesso em: 9 jun. 2020. 
SANTA CATARINA. Lei ${ }^{\circ} 15.113$, de 19 de janeiro de 2010. Dispõe sobre a implantação do programa de identificação e tratamento do transtorno do déficit de atenção e hiperatividade na rede estadual de ensino. Diário Oficial do Estado, Florianópolis, 20 jan. 2010.

SANTA CATARINA. Conselho Estadual de Educação de Santa Catarina. Resolução $n^{\circ} 100$, de 13 de dezembro de 2016. Estabelece normas para a educação especial no sistema estadual de educação de Santa Catarina. Diário Oficial do Estado, Florianópolis, 14 dez. 2016.

SANTA CATARINA. Conselho Estadual de Educação de Santa Catarina. Resolução $n^{0} 112$, de 12 de dezembro de 2006. Fixa normas para a educação especial no sistema estadual de educação de Santa Catarina. Diário Oficial do Estado, Florianópolis, 13 dez. 2006.

SANTA CATARINA. Secretaria de Estado da Educação - SED-SC. Política de educação especial. Florianópolis, 2018.

SANTOS, L. H.; FREITAS, C. R. TDAH, educação e cultura: uma entrevista com Ilina Singh (parte I). Interface: Comunicação Saúde Educação, Botucatu, v. 20, n. 59, p. 1077-1086, jul. 2016. https://doi.org/10.1590/1807-57622016.0565

SCHRAMM, F. R. Dialética entre liberalismo, paternalismo de estado e biopolítica: análise conceitual, implicações Bioéticas e democráticas. Bioética, Brasília, v. 22, n. 1, p. 10-17, mar. 2014.

SIMONETTI, L. Tomada de decisão: uma função executiva essencial. São Paulo: Secretaria de Planejamento e Gestão do Estado de São Paulo, 2015. (Transmissão de vídeo do YouTube). Disponível em: Goo.gl/7euuuq. Acesso em: 4 jul. 2020.

SPINK, M. J.; MEDRADO, B. Produção de sentido no cotidiano: uma abordagem teórico-metodológica para análise das práticas discursivas. In: SPINK, M. J. (org.). Práticas discursivas e produção de sentidos no cotidiano: aproximações teóricas e metodológicas. Rio de Janeiro: Centro Edelstein de Pesquisas Sociais, 2013. p. 22-41. Disponível em: Goo.gl/WwLUn6. Acesso em: 3 jul. 2020.

THOMAS, R. et al. Prevalence of attention-deficit/ hyperactivity disorder: a systematic review and meta-analysis. Pediatrics, Queensland, v. 135, n. 4, p. 994-1001, abr. 2015. https://doi.org/10.1542/peds.2014-3482 
UNITED NATIONS EDUCATIONAL, SCIENTIFIC AND CULTURAL ORGANIZATION - UNESCO. Declaração universal sobre bioética e direitos humanos (Dubdh). New York, 2005. Disponível em: goo.gl/zqQGi6. Acesso em: 6 out. 2020.

VEATCH, R. M. The foundations of bioethics. Bioethics, Quezon City, v. 13, n. 3/4, p. 206-217, jul. 1999.

WIENEN, A. W. et al. The advantages of an ADHD classification from the perspective of teachers. European Journal of Special Needs Education, London, v. 34, n. 5, p. 649-662, Feb. 2019. https://doi.org/10.1080/08856257.2019.1580838 


\section{ANEXO}

Quadro 1 - Mapa conceitual da beneficência

\section{Localização de elementos lexicais da Beneficência de Beauchamp \& Childress nas Diretrizes da Educação Especial de Santa Catarina}

\begin{tabular}{|c|c|c|}
\hline $1^{a}$ & $\begin{array}{l}\text { Política de } \\
\text { Educação } \\
\text { Especial - } \\
\quad 2006\end{array}$ & 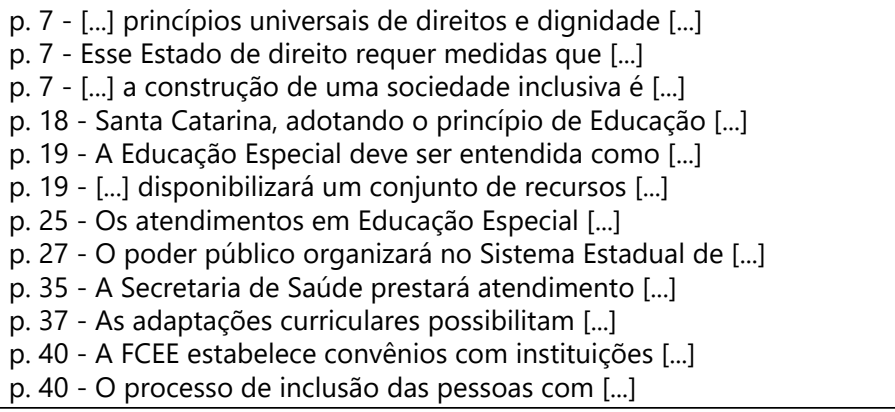 \\
\hline $2^{\mathrm{a}}$ & $\begin{array}{l}\text { Resolução } \\
n^{\circ} 112 \text { do } \\
\text { Conselho } \\
\text { Estadual de } \\
\text { Educação - } \\
\quad 2006\end{array}$ & $\begin{array}{l}\text { p. } 1 \text { - A Educação Especial integra o Sistema Estadual [...] } \\
\text { p. } 3 \text { - A Educação Especial, no âmbito do sistema de ensino [...] } \\
\text { p. } 3 \text { - A rede pública de ensino disponibilizará, [...] } \\
\text { p. } 4 \text { - As adequações curriculares envolvem a [...] } \\
\text { p. } 4 \text { - A avaliação do processo ensino e aprendizagem [...] } \\
\text { p. } 7 \text { - Serviço de atendimento educacional especializado [...] } \\
\text { p. } 7 \text { - A Política de Educação Especial para o [...] } \\
\text { p. } 8 \text { - Os profissionais que atuam na Educação Especial [...] }\end{array}$ \\
\hline $3^{a}$ & $\begin{array}{c}\text { Programa } \\
\text { Pedagógico } \\
\text { de Educação } \\
\text { Especial - } \\
2009\end{array}$ & 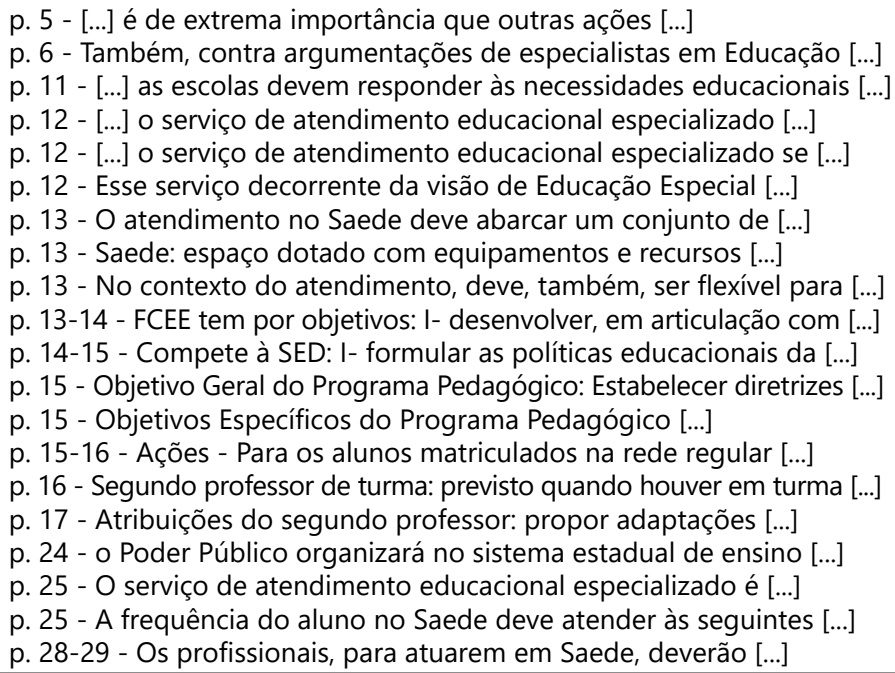 \\
\hline $4^{a}$ & $\begin{array}{l}\text { Resolução } \\
\mathrm{n}^{\circ} 100 \text { do } \\
\text { Conselho } \\
\text { Estadual de } \\
\text { Educação - } \\
2016\end{array}$ & $\begin{array}{l}\text { p. } 1 \text { - Entende-se por Educação Especial [...] } \\
\text { p. } 4 \text { - Atendimento educacional [...] }\end{array}$ \\
\hline
\end{tabular}

Fonte: Dados da pesquisa (2019) 


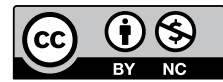

\section{Informações sobre as autoras}

Simone Schelbauer Moreira Paes: Mestre em Bioética. Professora do Estado de Santa Catarina. Integrante do Programa de Pós-Graduação em Bioética da Pontifícia Universidade Católica do Paraná. Contato: simonepaes6@gmail.com

iD https://orcid.org/0000-0001-5109-4842

Valquíria Elita Renk: Doutora em História da Educação. Professora Titular e pesquisadora do Programa de Pós-Graduação em Bioética e do Programa de Pós-Graduação em Direitos Humanos e Políticas Públicas da Pontifícia Universidade Católica do Paraná. Contato: valquiria.renk@pucpr.br

(iD) https://orcid.org/0000-0002-2679-7471

Daiane Priscila Simão-Silva: Doutora em Genética. Pesquisadora no Instituto para Pesquisa do Câncer. Integrante do Departamento Científico do mesmo instituto. Contato: dpscientist@gmail.com

(iD) https://orcid.org/0000-0002-1633-9899 